\title{
LEVANTAMENTO DE DADOS E ANÁLISE DE MUDANÇAS EM SISTEMAS FLUVIAIS POR MEIO DE GEOPROCESSAMENTO E SENSORIAMENTO REMOTO: PROPOSTA METODOLÓGICA E ESTUDO DE CASO
}

\author{
Otávio Cristiano Montanher \\ Universidade Estadual de Maringá, Departamento de Geografia, Maringá, PR, Brasil \\ otaviocmontanher@yahoo.com.br
}

\begin{abstract}
RESUMO
Levantamentos de dados a partir de produtos de sensoriamento remoto, como fotografias aéreas e imagens de satélite, têm sido extensivamente utilizados para recuperação de mudanças em sistemas fluviais. O objetivo deste artigo é apresentar uma metodologia para organização do levantamento e análise desse tipo de dados. A metodologia baseia-se na definição de segmentos de análise, distribuídos ao longo do vale aluvial. Esta definição é feita a partir do mapeamento da planície de inundação e do eixo central do vale. Posteriormente, devem ser definidos pontos ao longo desse eixo, bem como suas áreas de influência. A partir dos segmentos de análise e de objetos a serem mapeados, como o canal fluvial e os sedimentos expostos, foram propostos dois tipos de sínteses: espaço-temporal e longitudinal. A síntese espaçotemporal ainda é dividida em dois tipos, uma relativa ao canal e outra relativa à cobertura superficial da planície de inundação. Como são necessárias técnicas de geoprocessamento para aplicação da metodologia, o artigo apresenta opções com uso do software livre QGIS. Finalmente, um estudo de caso é apresentado como exemplo de aplicação da metodologia, cuja área situa-se no noroeste do Estado do Paraná.
\end{abstract}

Palavras-chave: Geomorfologia fluvial. Perfil longitudinal. mudanças espaçotemporais. imagens orbitais.

\section{DATA COLLECTION AND FLUVIAL SYSTEMS CHANGE ANALYSIS: METHODOLOGY BASED ON GEOPROCESSING AND REMOTE SENSING}

\begin{abstract}
Data collection by means of remote sensing products, as aerial photographs and orbital images, have been extensively used for retrieving fluvial systems changes. The aim of this article is to present a methodology for organizing both collection and analysis of this kind of dataset. The methodology is based on the definition of analysis segments, distributed along the alluvial valley. This definition is made by using both the mappings of the floodplain and the central axis of the valley. Posteriorly, must be determined points along that axis, as well as its influence areas. By using the analysis segments and objects to be mapped, such as the fluvial channel and exposed sediments, two types of synthesis were proposed: spatio-temporal and longitudinal. The spatio-temporal synthesis is divided into two kinds, one associated to the channel and another related to the floodplain superficial coverage. As geoprocessing techniques are required to apply the method, the article show options using the free Software QGIS. Lastly, a study case is presented to exemplify the application of the method, whose area is located in the northwest Paraná State.
\end{abstract}

Keywords: Fluvial geomorphology. Longitudinal profile. spatio-temporal changes. orbital images. 


\section{INTRODUÇÃO}

As mudanças em canais fluviais não se limitam apenas aos locais onde as intervenções foram impostas, por meio de obras, por exemplo, mas também para outros locais. Por sua vez, compreender as características e distribuição de tais efeitos nos canais fluviais é uma necessidade da geomorfologia (GREGORY, 1977). Posteriormente, Gregory (2006) afirma que, embora muitos processos de ajuste às mudanças dos sistemas fluviais sejam mais bem compreendidos, a predição da natureza e quantidade de prováveis mudanças em um local particular permanece um desafio em muitos casos específicos.

Como os rios possuem um controle dominante na formação de muitas paisagens, há um forte interesse na avaliação objetiva de métricas dos canais fluviais (GOLLY e TUROWSKI, 2017), no intuito de que a análise dos dados possa demonstrar parte da dinâmica da paisagem. Não só o levantamento dos dados permite a compreensão da paisagem, mas uma abordagem analítica adequada sobre essa base. A noção de sistemas, de Ludwig von Bertalanffy (BERTALANFFY, 2015), é uma opção comumente utilizada em geografia física para análise integrada desses dados.

O entendimento da noção de totalidade entre elementos que podem, muitas vezes, interagir de modo não linear ao formar um todo organizado, pode ser aplicado em ciências sociais, físicas e biológicas, constituindo um importante paradigma científico, a teoria geral dos sistemas (BERTALANFFY, 2015). A abordagem sistêmica constitui uma diretriz teórica muito utilizada em geografia física (BERTRAND, 2004), na compreensão de processos e formas em geomorfologia (STRAHLER, 1950; TRICART, 1977) e mais especificamente na geomorfologia fluvial (SCHUMM, 1977; STEVAUX e LATRUBESSE, 2017).

Essa abordagem, em teoria, permite avaliar relações complexas entre diferentes elementos de um sistema. No entanto, um ponto fracamente mencionado na literatura brasileira é que a análise dessas relações deve, muitas vezes, ser feita com bases de dados que permitam reconstituir a dinâmica do sistema, no espaço e no tempo. Portanto, as bases de dados devem possuir escalas espaciais e temporais compatíveis com as questões que estão sendo feitas na pesquisa.

Um exemplo, em geomorfologia fluvial, da necessidade de um bom planejamento da aquisição de dados para avaliação do sistema, é o levantamento de feições morfológicas de canais e de suas planícies de inundação. Como os processos de erosão, transporte e deposição, bem como suas formas resultantes estão conectados, a mudança em uma ou mais variáveis em um local específico do sistema pode resultar em mudanças nos mesmos processos (ou em outros processos), em diferentes lugares do sistema.

Neste artigo, objetiva-se apresentar uma metodologia, baseada em geoprocessamento e sensoriamento remoto, para a aquisição de dados e análise de mudanças ao longo de canais e planícies fluviais. Os produtos de sensoriamento remoto foram escolhidos por permitirem a avaliação da continuidade espacial do ajuste de formas e processos fluviais (GILVEAR e BRYANT, 2003; MONTANHER, 2013). É apresentada uma sequência de procedimentos para aquisição de dados sobre os próprios canais fluviais, bem como sobre as alterações morfológicas e na cobertura superficial dos depósitos fluviais. Muitos dos procedimentos de interpretação de imagens orbitais são rotineiros em trabalhos de mapeamento geomorfológico e em geoprocessamento. No entanto, a inovação da metodologia está no modo com que os dados são levantados e como as bases são posteriormente integradas e organizadas para análise.

Para aplicação da metodologia, sugere-se ao leitor o uso do software Qgis, por ter as ferramentas necessárias e por ser um software livre (QGIS DEVELOPMENT TEAM, 2009). Embora este artigo traz boa parte dos procedimentos descritos em detalhe, é interessante que o pesquisador já seja habituado com técnicas de geoprocessamento e tenha conhecimentos cartográficos básicos. Apesar do software em uso ser um aspecto tecnicamente importante, deve-se salientar que o aspecto científico relevante que deve ser observado neste artigo é o porquê de se realizar o levantamento de dados da forma como é apresentado. Isso porque muitos outros softwares podem ser utilizados, certamente por outros caminhos, mas forneceriam os mesmos resultados.

Como exemplo de aplicação da metodologia, é apresentado um estudo de caso do ribeirão Pinhalzinho II, situado no município de Umuarama, estado do Paraná. Esse sistema fluvial relativamente pequeno (extensão do canal principal $\approx 30 \mathrm{~km}$ ) apresenta um histórico complexo 
de mudanças em suas variáveis controladoras e respostas, em um curto intervalo temporal, o que tem chamado atenção da comunidade científica (FRANÇA JUNIOR, 2010; MONTANHER, 2013; FRANÇA JUNIOR e SOUZA, 2014; MONTANHER et al., 2014), justificando sua escolha como exemplo de aplicação.

\section{PESQUISAS ANTERIORES}

O uso de dados de sensoriamento remoto em mapeamentos da paisagem é um procedimento tradicional em geografia física (BERTRAND, 2004) e também especificamente em geomorfologia fluvial (GILVEAR e BRYANT, 2003). Ainda recentemente, muitos trabalhos têm utilizado fotografias aéreas e imagens orbitais para o levantamento de mudanças planimétricas de canais fluviais, tanto em contexto nacional (SANTOS e PINHEIRO, 2002; RODRIGUES, 2005; KLEINA et al., 2014; PINTON e CUNHA, 2015; QUEIROZ et al., 2018), quanto internacional (DOWNWARD et al., 1994; LEYS e WERRITTY, 1999; GOLLY e TUROWSKI, 2017; SCHWENK et al., 2017). Mais especificamente, algumas dessas contribuições demonstram, além de estudos de caso, metodologias para o tratamento desses tipos de dados em ambientes de sistemas de informação geográfica (SIG), sendo generalizáveis para outras áreas, o que corresponde à proposta desta pesquisa. Algumas dessas pesquisas estão detalhadas em sequência.

Downward et al. (1994) descrevem metodologias para o georreferenciamento de mapas históricos e fotografias aéreas, digitalização dos canais e a transformação dos vetores dos canais fluviais para arquivos matriciais binários (do tipo 0 e 1). Estes autores sugerem três tipos de análise sobre essa base de dados: i) sobreposição simples entre os vetores dos canais; ii) combinação de dois arquivos matriciais para geração de um novo arquivo de mudanças; iii) combinação de diversos arquivos matriciais para geração de um novo produto, denominado estabilidade histórica.

Leys e Werritty (1999) utilizaram o pacote ER Mapper, disponível no software ERDAS, para o tratamento de diversas fotografias aéreas obtidas em uma área de estudo situada no sul da Escócia. Os autores sugerem quatro índices para descrição e quantificação de mudanças planimétricas em canais fluviais: i) migração lateral do centro do canal, incluindo a migração total e taxas de mudança; ii) mudanças na largura do canal e na razão entre a largura do canal atual e a largura da planície de inundação ocupada pelo canal durante o período de análise; iii) área de sedimentos ativos e área ocupada pelo canal atual; iv) sinuosidade do canal. Alguns dos índices propostos por Leys e Werritty (1999) são semelhantes à proposta desta pesquisa, no entanto, esse pacote não é aplicado em um software de acesso gratuito.

Schwenk et al. (2017) apresentam o pacote denominado RivMAP, implementado em ambiente MATLAB. Os autores fazem uso de classificações realizadas em uma série multitemporal de imagens orbitais, diferenciadas em duas classes: "água" e "outros". A partir dos arquivos matriciais dos canais (classificação da área de água) os autores obtêm uma série de índices: largura do canal, migração lateral, acreção, erosão, corte de pedúnculos, entre outros índices que podem ser definidos pelo usuário. Os autores apresentam uma análise no rio Ucayali (Perú) a partir de imagens do programa Landsat, entre 1985 e 2015. A desvantagem desse pacote é que o software MATLAB não é de acesso gratuito. Schwenk et al. (2017) ainda apresentam uma revisão de cinco pacotes computacionais que realizam análises morfométricas de canais fluviais, baseados nos seguintes softwares e linguagens de programação: ArcGIS, IDL e MATLAB, em que alguns deles não são de acesso gratuito ou necessitam do usuário algum grau de familiaridade com programação.

Golly e Turowski (2017) apresentam o pacote denominado CMGO, executável no software gratuito R (R CORE TEAM, 2017), para obtenção de índices planimétricos dos canais fluviais, como o comprimento, largura, migração das margens, e altimétricos, como a declividade (caso haja disponibilidade de dados altimétricos). A informação básica para obtenção dos índices planimétricos é um vetor contendo as margens dos canais, podendo ser obtida tanto em campo como por meio de dados de sensoriamento remoto. Apesar do fato de que a ferramenta apresentada por Golly e Turowski (2017) é de acesso gratuito, ela foi implementada em ambiente computacional $\mathrm{R}$, um dos softwares livres mais utilizados em análises científicas de dados em um contexto mundial, mas ainda pouco difundido na geografia brasileira. Sua interface, por meio 
de linhas de comando, é pouco atrativa para usuários não habituados com esta interface computacional. Outra desvantagem do pacote CMGO é que ele gera apenas índices relativos aos canais fluviais, não tratando a morfologia e da planície de inundação e a dinâmica dos sedimentos.

Nesta revisão bibliográfica não foram encontrados pacotes computacionais, ou desenvolvimentos metodológicos semelhantes aos mencionados (RivMAP, CMGO), que tenham sido desenvolvidos em contexto nacional. Também se percebeu que alguns pacotes computacionais já existentes exigem noções básicas de programação por parte do usuário e/ou não são de acesso gratuito. Portanto, a metodologia disponibilizada neste artigo busca atender pesquisas que não tenham apoio financeiro para a finalidade em questão e usuários que não tenham afinidade com programação.

\section{APRESENTAÇÃO DA METODOLOGIA}

A metodologia proposta baseia-se no uso do sensoriamento remoto como via para obtenção de dados primários (Figura 1). A definição de quais variáveis podem ser analisadas depende da compatibilidade entre a dimensão dos objetos mapeados e da resolução dos dados (compatibilidade entre escalas temporais e espaciais). Este artigo trata de três grupos de variáveis: área e eixo linear do vale aluvial, área e posição linear do centro do canal fluvial e área de sedimentos expostos. Após a descrição de cada variável, são apresentadas opções para sintetização dos dados por meio de duas opções: i) produtos cartográficos que apresentam sínteses dinâmicas (temporais) do sistema fluvial, e ii) gráficos que apresentam as variações longitudinais.

Figura 1 - Fluxograma descritivo das etapas da metodologia para avaliação espaço-temporal de mudanças em sistemas fluviais, com base em dados de sensoriamento remoto.

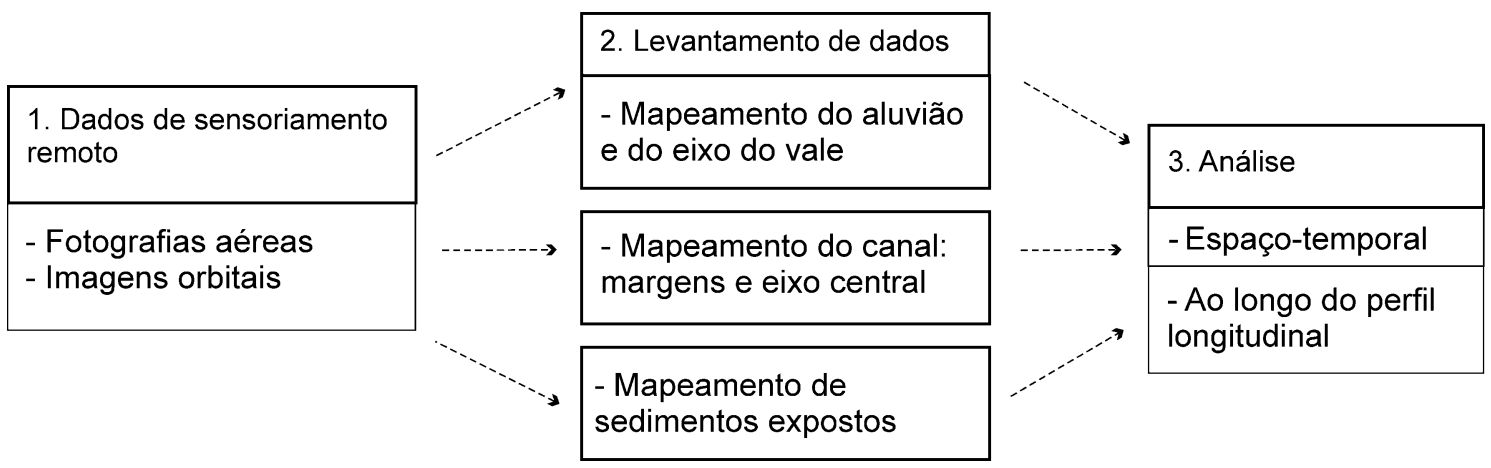

\section{MAPEAMENTO DOS DEPÓSITOS FLUVIAIS}

A primeira etapa é determinar a extensão do sistema planície de inundação-canal a ser estudado.

Após a definição de um trecho da planície de inundação como objeto de levantamento, o primeiro passo é seu mapeamento. Esse procedimento visa delimitar a atual área onde possa haver alguma dinâmica associada com as mudanças impostas ao sistema fluvial (mudanças nos canais, na cobertura vegetal, nos depósitos, etc.). O mapeamento do aluvião deve ser feito por meio de um vetor do tipo polígono.

O mapeamento de depósitos fluviais depende dos conhecimentos em geomorfologia fluvial do intérprete, e muitas vezes também da relação entre vegetação e o substrato, aplicados à interpretação das fotografias aéreas e/ou imagens orbitais. No que se refere às morfologias fluviais, a identificação dos canais, paleocanais, lagoas, barras, diques marginais e leques de espraiamento indicam a extensão da planície de inundação. Por outro lado, o desenvolvimento da vegetação sobre os depósitos fluviais pode mascarar algumas dessas feições. Nesses casos, torna-se necessário interpretar a própria vegetação como indicador dos limites da planície de inundação. As relações entre vegetação e as morfologias fluviais são úteis para determinar, entre 
outras informações, o estágio da recuperação da vegetação ripária após um distúrbio, por exemplo (OSTERKAMP e HUPP, 2009).

O elevado nível freático no vale aluvial em relação à superfície, imposta pelo baixo gradiente topográfico (ou declividade) faz com que, muitas vezes, os solos permaneçam constantemente saturados em água nas planícies de inundação. Enquanto algumas espécies de plantas, principalmente arbóreas, não são adaptadas a essas condições, outras ocorrem apenas nessas condições (OSTERKAMP e HUPP, 2009). Portanto, o excesso de umidade como fator limitante da distribuição das espécies faz com que haja uma diferença significativa entre a vegetação adaptada à dinâmica hidrogeomorfológica da planície de inundação e aquela que ocupa as vertentes da bacia hidrográfica.

Neste trabalho, é apresentado o mapeamento da planície de inundação do ribeirão Pinhalzinho II, que deve ser notado apenas como exemplo de aplicação. Isso porque cada sistema específico pode conter diferentes tipos de relação entre os depósitos fluviais e a vegetação e diferentes tipos de formas fluviais. Portanto, o mapeamento depende basicamente do conhecimento da área pelo intérprete, adquirido por meio de bibliografia e incursões a campo. Mapeamentos da vegetação em áreas de depósitos fluviais do rio Paraná, sujeitas às variações do nível freático e às inundações, podem ser consultados em Fragal et al. (2012) e Souza Filho e Fragal (2013), por exemplo.

\section{DEFINIÇÃO DE SEGMENTOS DE ANÁLISE}

Após o mapeamento da planície de inundação, ela deve ser dividida em segmentos, que se dispõem de forma longitudinal. Cada segmento será uma unidade de análise da planície de inundação, as quais servem para a aquisição de dados de forma que se possa localizar cada valor em sua posição no perfil longitudinal. É necessário esclarecer que o conceito tradicional de perfil longitudinal, como um gráfico constituído das variáveis altitude do leito do canal e distância horizontal ao longo do canal (STEVAUX e LATRUBESSE, 2017) não é o utilizado neste trabalho. O perfil longitudinal, nesta metodologia, se refere à plotagem gráfica entre a distância ao longo do eixo do vale (não do canal) e qualquer uma das variáveis em estudo, como a largura média do canal em cada segmento, por exemplo.

A primeira etapa para a definição dos segmentos é o mapeamento do eixo do vale. O eixo do vale é sempre igual ou menor do que a extensão de um rio no mesmo trecho, pois enquanto o rio pode ser sinuoso, como é típico de rios meandrantes, o vale possui uma direção que se altera de forma mais suave. A delimitação do eixo do vale referida é a mesma utilizada para o cálculo do índice de sinuosidade tradicional (CHRISTOFOLETTI, 1980), exemplificada na Figura 2. A delimitação do eixo do vale deve ser feita por meio de um vetor do tipo linha.

Figura 2 - Exemplo hipotético dos elementos mencionados no texto, contendo a distinção entre um canal fluvial e o eixo do vale aluvial. O canal é representado pela linha azul, enquanto que o eixo do vale é representado pela linha pontilhada vermelha. As linhas pontilhadas pretas representam o limite entre a planície de inundação (P.I.), e as vertentes (V.), existentes nas duas laterais.

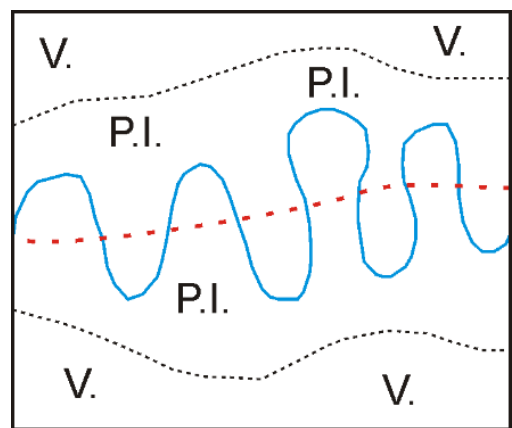

Após a obtenção do eixo do vale, utiliza-se a ferramenta disponível em: "Geoalgoritmos Qgis $\rightarrow$ Ferramentas de Geometria Vetorial $\rightarrow$ Create Points Along Lines”, para obtenção de pontos ao longo desse eixo, em distância fixa, sendo que a distância entre os pontos deve ser definida pelo 
usuário. Essa etapa é de suma importância, pois define o nível de detalhamento do levantamento de dados ao longo do eixo longitudinal da planície de inundação. Por exemplo, para uma planície de inundação cujo eixo tenha $600 \mathrm{~m}$ de extensão, se for definida uma distância de $100 \mathrm{~m}$, haverá sete pontos (e sete segmentos) com mesmo espaçamento entre si. O mesmo trecho pode ser avaliado conforme uma equidistância de $200 \mathrm{~m}$, resultando em quatro segmentos (Figura 3).

Os pontos já definidos conforme uma distância fixa são utilizados para geração de uma série de segmentos ao longo da planície de inundação, em que cada ponto gera uma área de influência. A extrapolação espacial de pontos para áreas pode ser feita com uso do diagrama de Vonoronoi. No software Qgis, os polígonos de Voronoi podem ser obtidos em: "Vetor $\rightarrow$ Geometrias $\rightarrow$ Polígonos de Voronoi". A caixa de diálogo que se abre, denominada "Polígonos de Voronoi" requisita os pontos de entrada, gerados a partir do processo anterior (Figura 4). Adicionalmente, há uma opção denominada "Região de Buffer". Quanto maior é o valor de Buffer, mais os polígonos são estendidos para além dos limites dos pontos. É necessário aumentar o valor de Buffer até que os polígonos gerados nesse processo abranjam o polígono gerado no mapeamento da planície de inundação.

Figura 3 - Definição dos segmentos de análise de uma planície de inundação. A - Trecho total hipotético em estudo. B - Diferenciação em segmentos com distância fixa de 100 m e 200 m. C - Área de influência de cada ponto.

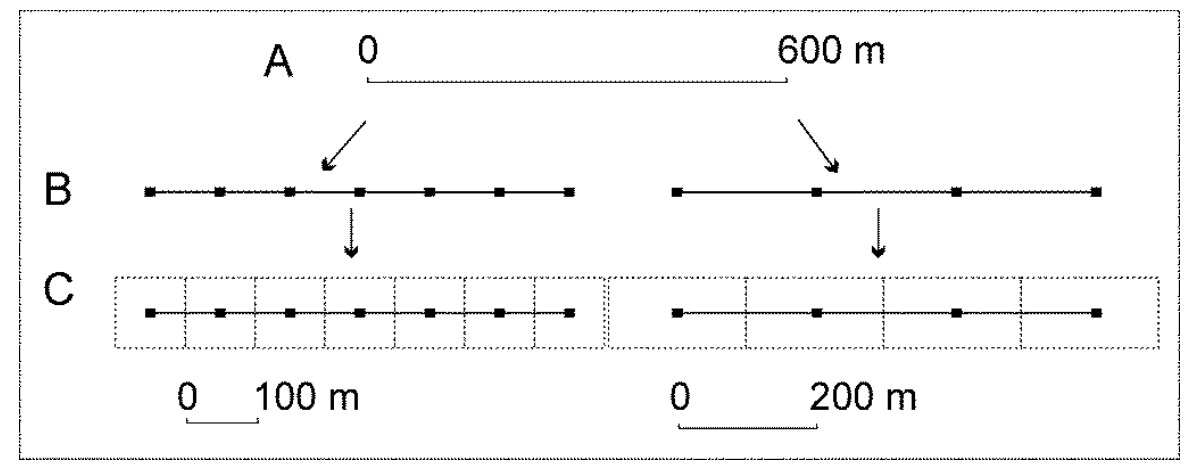

Figura 4 - A - Caixa de diálogo "Polígonos de Voronoi". A camada de entrada é o vetor contendo os pontos, e a região de Buffer define o quanto os polígonos são estendidos para além dos limites dos pontos. B - Exemplo do resultado dos polígonos de Voronoi para o ribeirão Pinhalzinho (Umuarama PR): A linha vermelha contendo pontos é o eixo do vale, com distância fixa de $150 \mathrm{~m}$; as duas linhas verdes representam os limites da planície de inundação; os polígonos pretos são as áreas de influência resultantes do diagrama de Voronoi. Observe que os polígonos foram estendidos para além dos limites da planície de inundação.
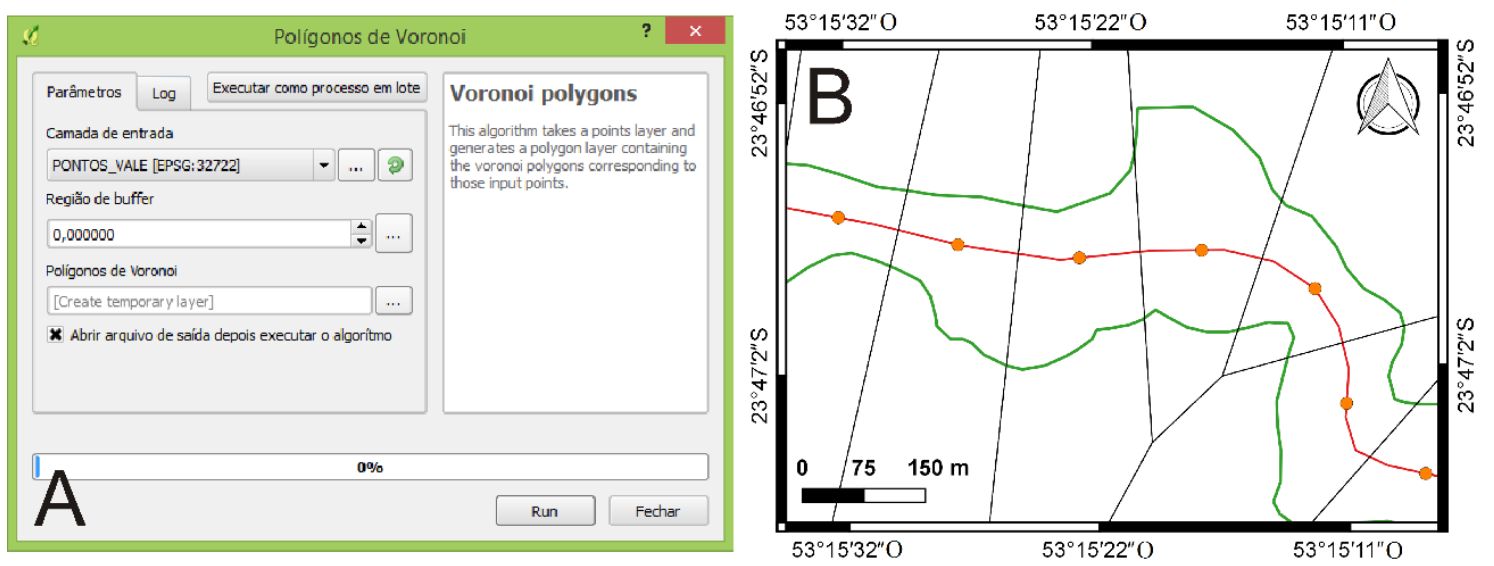

O último passo para obtenção dos segmentos de levantamento de dados da planície de inundação é o recorte dos polígonos de Voronoi pelo polígono delimitado a partir do mapeamento da planície de inundação. A caixa de diálogo "Recortar" encontra-se em: "Vetor $\rightarrow$ 
Geoprocessamento $\rightarrow$ Recortar", (Figura 5), em que os polígonos de Voronoi devem ser a camada de entrada e o polígono contendo a planície de inundação deve ser a camada de corte. O polígono resultante desse procedimento contém os segmentos de interesse e deve ter, em sua tabela de atributos, uma coluna denominada "Distance" (gerada automaticamente por este processo), a qual indica em qual posição do perfil longitudinal o segmento se encontra.

Figura 5 - Caixa de diálogo "Recortar". A camada de entrada é o arquivo contendo os polígonos de Voronoi e a camada de corte é o arquivo que contém o mapeamento da planície de inundação.

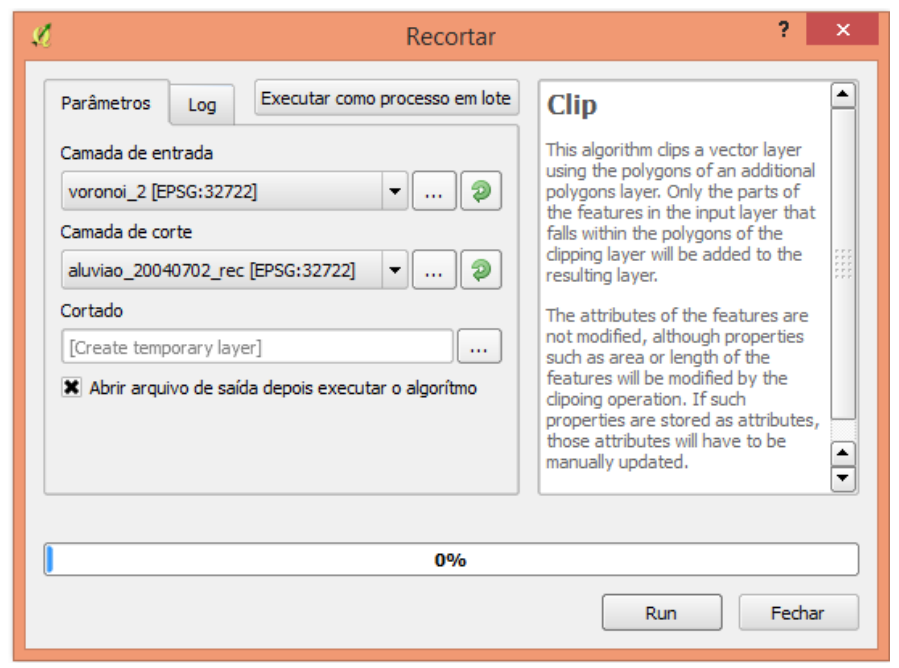

\section{AQUISIÇÃO DE DADOS \\ ÁREA DO SEGMENTO (As)}

A primeira informação que pode ser adquirida é a área de cada segmento (variável $A_{s}$ ). Como a distância entre os pontos é fixa, uma área maior significa que a planície de inundação possui uma dimensão, transversal ao vale, maior. A largura da planície de inundação pode estar relacionada com diferentes gradientes do canal, mudanças litológicas, diferentes padrões de canais, entre outros fatores que se apresentam como informação básica para a interpretação da geomorfologia local.

A obtenção da área pode ser feita a partir da edição da tabela de atributos, sendo necessário criar um novo campo. O campo pode ser do tipo "Número decimal", e a fórmula a ser preenchida encontra-se em "Calculadora de campo $\rightarrow$ Geometria $\rightarrow$ \$area", a qual retorna a área de cada segmento do perfil, na unidade de $\mathrm{m}^{2}$.

\section{EXTENSÃO DO CANAL (C)}

A extensão total de canais fluviais (variável C) pode ser obtida para cada segmento a partir do mapeamento do canal, por meio de um vetor (linha) e seu cruzamento com o polígono que contém os segmentos. O procedimento necessário é o seguinte: "Vetor $\rightarrow$ Geoprocessamento $\rightarrow$ Interseção", em que a camada de entrada é um vetor (linha) contendo o canal, e a camada de cruzamento é o vetor (polígono), contendo os segmentos da planície de inundação (Figura 6).

O resultado do procedimento é um vetor (linha), idêntico ao original, mas é dividido conforme os segmentos da planície de inundação. A obtenção da extensão pode ser feita a partir da edição da tabela de atributos, sendo necessário criar um novo campo. O campo pode ser do tipo "Número decimal", e a fórmula a ser preenchida encontra-se em "Calculadora de campo $\rightarrow$ Geometria $\rightarrow$ \$length", a qual retorna a extensão linear dos canais em cada segmento do perfil, na unidade de $\mathrm{m}$. 
Figura 6 - Caixa de diálogo "Interseção". A camada de entrada é o arquivo vetorial (linha) que delimita os canais fluviais, e a camada de cruzamento é o arquivo vetorial (polígono) que contém os segmentos da planície de inundação.

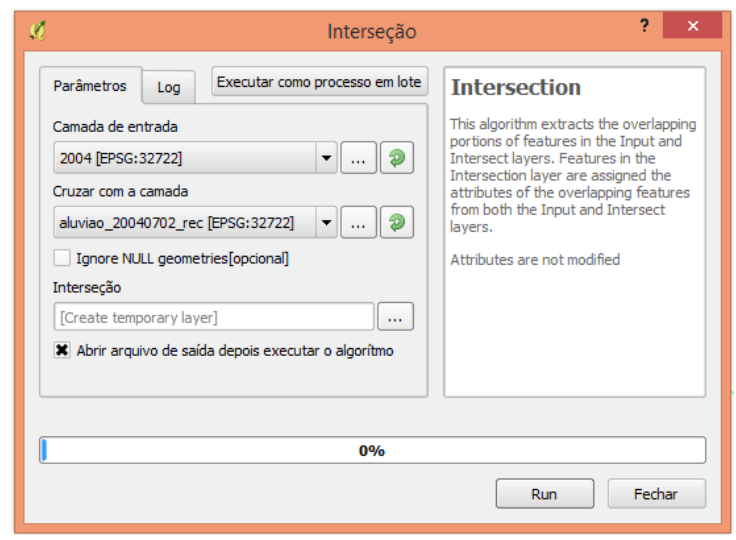

\section{SINUOSIDADE (S)}

Nesta proposta, o índice de sinuosidade, conforme descrito por Christofoletti (1980), pode ser obtido para cada segmento definido ao longo da planície de inundação:

$$
S=\frac{C}{V}
$$

Em que:

$\mathrm{S}=$ índice de sinuosidade (adimensional);

$\mathrm{C}=$ extensão do canal $(\mathrm{m})$;

$\mathrm{V}=$ extensão do eixo do vale, no mesmo trecho em que $\mathrm{C}$ foi mensurado $(\mathrm{m})$.

A extensão total do canal foi obtida por meio do procedimento de Interseção, definido no tópico anterior. A distância relativa ao eixo do vale (V) deveria ser a mesma definida pela soma das distâncias entre os pontos (no estudo de caso deste trabalho, a distância foi de $150 \mathrm{~m}$ ). No entanto, o primeiro e o último segmentos não têm, necessariamente, essa distância, e devido ao fato de que os polígonos de Voronoi não são necessariamente ortogonais ao eixo do vale, variações pequenas podem existir. Para resolver esses problemas recomenda-se repetir 0 procedimento de Interseção para o vetor que contém o eixo do vale, para se obter a distância exata de $\mathrm{V}$ para cada segmento.

Nesse caso, a camada de entrada é um vetor linear contendo o eixo do vale, e a camada de cruzamento é o vetor poligonal, contendo os segmentos da planície de inundação. A obtenção da extensão do eixo do vale, após o procedimento de Interseção, deve ser feita a partir da edição da tabela de atributos, da mesma forma que mencionado no tópico que aborda a obtenção da extensão do canal.

\section{LARGURA DO CANAL (L)}

O canal fluvial pode ser facilmente reconhecido e delimitado por meio de interpretação de produtos de sensoriamento remoto, desde que sua dimensão seja compatível com a escala das imagens. No entanto, um problema inerente à medição em seções pontuais é a especificidade do valor. Efeitos locais podem fazer com que hajam variações na largura do canal (L), de forma que a medida pontual pode ou não ser próxima ao valor médio do trecho avaliado.

A solução proposta é a avaliação de larguras médias das seções em cada segmento de análise. Para isso, primeiramente é necessário mapear o canal por meio de um vetor do tipo polígono. Após a obtenção desse vetor, é necessário aplicar novamente o procedimento de interseção, descrito no tópico de extensão dos canais ("Vetor $\rightarrow$ Geoprocessamento $\rightarrow$ Interseção"). Nesse 
caso, a interseção deve ser feita entre o vetor que contém o polígono do canal mapeado (camada de entrada) e a camada de cruzamento é o arquivo vetorial (polígono) que contém os segmentos da planície de inundação.

$O$ arquivo vetorial resultante é um polígono do canal dividido em partes conforme os segmentos da planície de inundação. O próximo passo é a obtenção da área de canal $\left(A_{c}\right)$ em cada segmento. Isso pode ser feito a partir da edição da tabela de atributos. O campo pode ser do tipo "Número decimal", e a fórmula a ser preenchida encontra-se em "Calculadora de campo $\rightarrow$ Geometria $\rightarrow$ \$area", a qual retorna a área de cada segmento, na unidade de $\mathrm{m}^{2}$. Esse procedimento retorna a área total do canal em cada segmento, em que para se obter sua largura média:

$$
L=\frac{A_{c}}{C}
$$

Em que:

$\mathrm{L}=$ largura média $(\mathrm{m})$;

$A_{c}=$ área dos canais fluviais $\left(\mathrm{m}^{2}\right)$.

\section{ÁREA DE SEDIMENTOS EXPOSTOS $\left(\mathrm{A}_{\mathrm{E}}\right)$}

Conforme base teórica exposta por Tricart (1977), a capacidade da vegetação em se fixar em determinado substrato depende da intensidade dos processos morfodinâmicos (erosão, transporte e deposição) atuantes sobre ele. Portanto, a presença e a fisionomia da vegetação (herbácea ou arbustiva, por exemplo) é um bom indicador dos processos morfodinâmicos de uma área. Essa base teórica é utilizada como apoio neste trabalho para avaliação dos processos morfodinâmicos atuantes ao longo da planície de inundação. Entende-se que as áreas de sedimentos expostos (não cobertas por vegetação), passaram por processos recentes de erosão ou deposição, de forma que não houve tempo para o estabelecimento da vegetação. Portanto, o mapeamento dos sedimentos expostos indica, de modo geral, as áreas que estariam passando por processos morfodinâmicos recentes, enquanto que as áreas cobertas por vegetação estariam mais estáveis (estabilidade que considera apenas o intervalo temporal da série de imagens analisada).

Para se realizar o mapeamento das áreas de sedimentos expostos, propõe-se o uso da classificação de imagens, técnica extensivamente utilizada em processamento digital de imagens, constituindo-se na atribuição de rótulos para cada pixel da imagem, em função de suas propriedades espectrais e/ou espaciais (NOVO, 2010). A classificação, neste caso, visa separar a planície de inundação em duas classes: "sedimentos expostos" e "outros", em que a última classe abrange a vegetação, sombras e corpos hídricos. Diversos métodos de classificação podem ser utilizados para esse procedimento, cuja escolha depende da quantidade de bandas espectrais da imagem, da possibilidade do uso de propriedades espaciais e da experiência do usuário, entre outros fatores. Para este trabalho, foi utilizado o método de máxima verossimilhança, devido à dois fatores: i) existência de forte diferenciação espectral entre os sedimentos e os outros alvos da área de estudo e ii) a maior parte das imagens utilizadas são pancromáticas (banda única).

Os seguintes passos descrevem o uso das imagens classificadas para o cálculo da área de sedimentos expostos $A_{E}\left(\mathrm{~m}^{2}\right)$ em cada segmento. Ao se realizar a classificação, deve-se atribuir o valor 1 para as áreas de sedimentos recentes e 0 para o restante dos alvos. Após a classificação, pode-se contar a quantidade de pixels que foram classificados como "sedimentos expostos" a partir do seguinte caminho: "Geoalgoritmos QGIS $\rightarrow$ Ferramentas do Raster $\rightarrow$ Estatísticas Zonal". A caixa de diálogo "Estatísticas Zonal" está representada na Figura 7.

A tabela de atributos do arquivo de saída, resultante desse procedimento, contém uma série de estatísticas descritivas, em que a coluna "SUM" apresenta a soma de todos os pixels em cada segmento. Como cada pixel de sedimentos expostos possui valor 1 e todos os outros possuem o valor 0 , a soma total refere-se à quantidade de pixels de sedimentos em cada segmento. Para se obter a área de sedimentos em cada segmento, é necessário multiplicar a soma desses pixels pela área de cada pixel da imagem que está sendo utilizada. 


$$
A_{E}=N_{p} \cdot R^{2}
$$

Em que:

$A_{E}=$ área de sedimentos expostos $\left(m^{2}\right)$;

$\mathrm{N}_{\mathrm{p}}=$ número de pixels em cada segmento;

$R=$ resolução da imagem $(\mathrm{m})$.

Figura 7 - Caixa de diálogo "Estatísticas Zonal". A camada de entrada é o arquivo matricial (camada raster) que contém as duas classes ( $1=$ "sedimentos expostos" e $0=$ "outros"). A camada vetor é o arquivo vetorial (polígono) que contém os segmentos da planície de inundação.

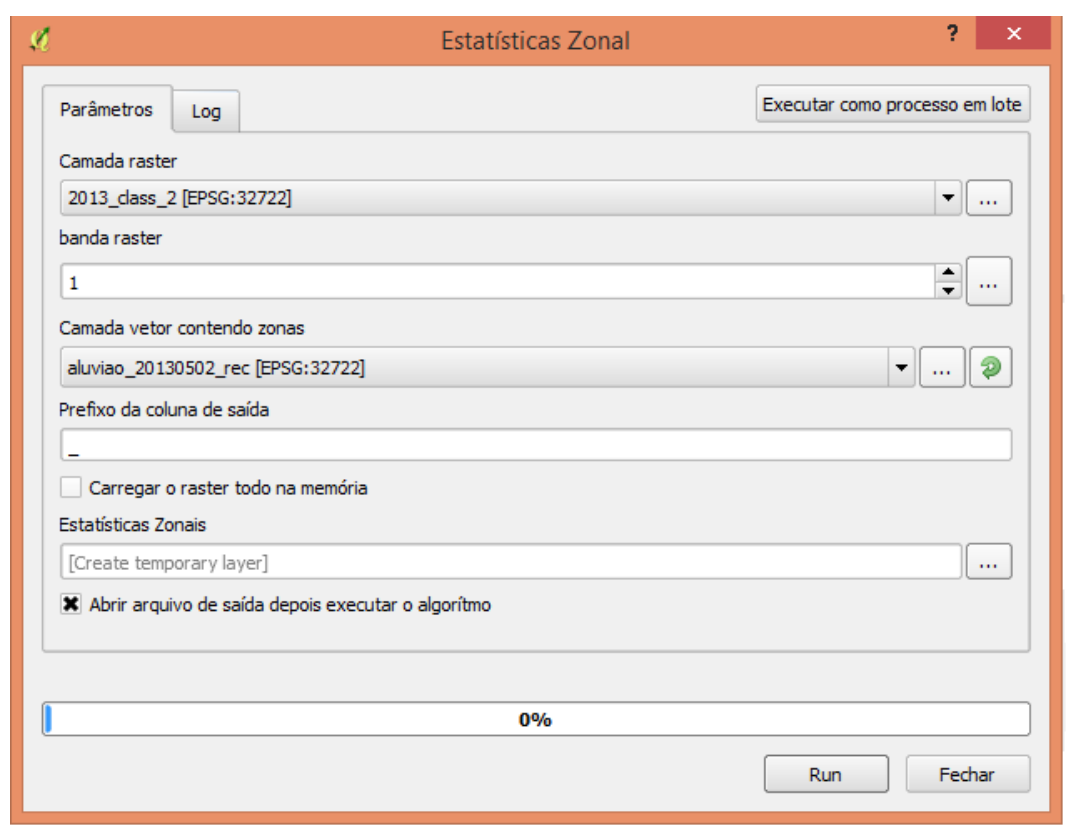

\section{SÍNTESES ESPAÇO-TEMPORAIS}

A classificação dos sedimentos expostos ao longo de sucessivas imagens permite a geração de um banco de dados cuja análise das mudanças espaço-temporais é dificultada pela quantidade de informações. A mesma questão é feita para a variação temporal da posição do canal fluvial. A síntese cartográfica, em apreciação dinâmica, é uma solução adequada para análise desses casos (MARTINELLI, 2016).

A primeira proposta para a síntese dos processos morfodinâmicos é a soma dos arquivos matriciais obtidos pelo processo de classificação. Como os pixels de sedimentos expostos possuem valor 1 e o restante dos pixels de cada arquivo possuem valor 0 , a soma de diversos arquivos fornece a quantidade de vezes em que houve sedimento exposto em determinada área. Esse resultado dividido pelo número total de imagens e posterior multiplicação por 100 resulta em um novo arquivo matricial, que fornece o percentual de datas em que houve sedimento exposto em cada pixel, em relação ao total de datas avaliadas:

$$
\text { Síntese } e_{1}=\frac{\sum_{i=1}^{n} M_{i}}{n} \cdot 100
$$

Em que:

$\mathrm{M}_{\mathrm{i}}=$ valor do pixel classificado ( 0 ou 1 ) em cada arquivo matricial;

$\mathrm{n}=$ número total de imagens classificadas; 
No QGIS, os cálculos sobre arquivos matriciais podem ser feitos em: "Raster $\rightarrow$ Calculadora Raster". A segunda síntese dinâmica proposta segue a mesma lógica da anterior, mas é aplicada ao canal fluvial. Cada polígono do canal fluvial (em cada data) deve ser transformado para um arquivo matricial: "Raster $\rightarrow$ Converter $\rightarrow$ Vetor para Raster". No entanto, é necessário anteriormente criar uma variável numérica na tabela de atributos, em que o valor deve ser 1. Dessa maneira, ao se criar o arquivo matricial, os pixels com valor 1 referem-se ao canal e os pixels com valor 0 referem-se ao restante da área. A síntese relativa à dinâmica espaço-temporal do canal fluvial é, portanto:

$$
\text { Síntese }_{2}=\frac{\sum_{i=1}^{n} c_{i}}{n} \cdot 100
$$

Em que:

$\mathrm{C}_{\mathrm{i}}=$ valor do polígono rasterizado ( 0 ou 1$)$ em cada arquivo matricial;

$\mathrm{n}=$ número total de matrizes geradas;

Assim como a equação 4, a equação 5 também resulta em valores de porcentagem, mas nesse caso a proporção refere-se à quantidade de datas em que o canal esteve em um determinado local. A síntese 1 pode facilitar a interpretação de processos como a evolução de barras laterais, o retrabalhamento de barras centrais e a deposição de sedimentos sobre as planícies, bem como em leques de espraiamento, por exemplo. Por outro lado, a síntese 2 tem como objetivo a análise de processos relacionados com as mudanças planimétricas do canal, como a migração de meandros e processos avulsivos, bem como a identificação de trechos estáveis.

\section{SÍNTESES LONGITUDINAIS}

Após a obtenção das variáveis mencionadas até este ponto da metodologia, cuja disposição orienta-se ao longo de segmentos da planície, pode-se avaliar a dependência espacial dos fenômenos de erosão e deposição, por exemplo, bem como suas variações temporais. No entanto, para canais cuja extensão se altera consideravelmente no decorrer do tempo, o uso do perfil longitudinal tradicional, em que a distância horizontal (abcissa) é a mesma do próprio canal, a comparação entre datas é dificultada. No estudo de caso apresentado, em Umuarama (PR), por exemplo, em um trecho aluvial de $12 \mathrm{~km}$, as seguintes extensões totais do canal principal foram mensuradas: 2004: $13.996 \mathrm{~m}$; 2008: $14.395 \mathrm{~m}$; 2010: $14.167 \mathrm{~m} ; 2016$ : $14.434 \mathrm{~m}$. A diferença entre as datas de maior e menor extensão é de $437 \mathrm{~m}$, indicando que o canal se ajusta rapidamente às condições hidrológicas da bacia.

O fato de que o canal pode ser mais ou menos sinuoso, ao longo do tempo, prejudica o uso da distância horizontal para as comparações longitudinais. A solução proposta para esse problema é o uso da distância horizontal ao longo do eixo do vale $\left(H_{v}\right)$. Cada variável obtida $\left(A_{s}, C, S, L\right.$, $\left.A_{E}\right)$ pode ser representada graficamente ao longo de $H_{\vee}$ para cada data de aquisição de dados. Adicionalmente, podem ser obtidas derivadas para cada período de tempo $(\Delta T)$ desejado, resultando na quantificação da mudança da variável:

$$
X_{T}=\frac{X_{j}-X_{i}}{T_{j}-T_{i}}
$$

Em que:

$\mathrm{X}=$ variável a ser analisada;

$T=$ tempo (anos decimais). 
Para a equação 6, j e i se referem aos valores final e inicial, respectivamente, da variável $X$ e de tempo T. O tempo deve ser contabilizado em anos decimais, que pode ser obtido a partir da soma entre o ano corrente e a razão entre o dia juliano por 365 (ou 366, em anos bissextos). Para exemplificar a aplicação da equação 6 , foram utilizadas medições da largura do canal $(L)$ principal do ribeirão Pinhalzinho, em duas datas (Tabela 1). $\mathrm{O}$ valor de $\Delta \mathrm{L}$ negativo indica que houve diminuição de 6,8 $\mathrm{m}$ na largura do canal para um trecho específico, entre as duas datas. Posteriormente, a razão pelo $\Delta T$ normaliza $L$ pelo tempo, permitindo a comparação com outros períodos de tempo.

Tabela 1 - Exemplo de aplicação da equação 6 para valores de largura do canal do ribeirão Pinhalzinho II

\begin{tabular}{|c|c|c|c|c|c|}
\hline Data & $\mathrm{T}$ (anos) & $\Delta \mathrm{T}$ (anos) & $L(m)$ & $\Delta \mathrm{L}(\mathrm{m})$ & $\mathrm{LT}_{\mathrm{T}}(\mathrm{m} / \mathrm{ano})$ \\
\hline $02 / 07 / 2004$ & 2004,501 & \multirow{2}{*}{1,449} & 13,33 & \multirow{2}{*}{$-6,8$} & \multirow{2}{*}{$-4,69$} \\
\hline $14 / 12 / 2005$ & 2005,95 & & 6,53 & & \\
\hline
\end{tabular}

\section{EXPORTANDO DADOS EM PLANILHA}

Após a obtenção das variáveis descritas, muitas vezes é necessário manusear a série de dados por meio de planilhas eletrônicas e/ou softwares específicos para o tratamento estatístico dos dados. Embora haja diversos caminhos para se realizar esse procedimento, indica-se um caminho a seguir no QGIS. Para exportar a base de dados salva em uma tabela de atributos, deve-se ir em "Salvar Como... $\rightarrow$ Formato $\rightarrow$ MS Office Open XML spreadsheet". O arquivo resultante dessa exportação pode ser aberto no software Excel, por exemplo.

\section{ESTUDO DE CASO: UMUARAMA (PR)}

\section{ÁREA DE ESTUDO E MATERIAIS}

A área selecionada para o estudo de caso foi o ribeirão Pinhalzinho II, situado no município de Umuarama, noroeste do estado do Paraná (Figura 8). Este é um sistema fluvial de quinta ordem, cujo canal principal possui aproximadamente $24 \mathrm{~km}$ de extensão. A área total da bacia hidrográfica é de $186 \mathrm{~km}^{2}$ (FRANÇA JÚNIOR, 2010), com área urbana ocupando aproximadamente $12 \mathrm{~km}^{2}$ do setor das cabeceiras de drenagem.

De toda sua extensão, selecionou-se um trecho de aproximadamente $13 \mathrm{~km}$ do ribeirão Pinhalzinho II, conforme ilustrado na Figura 8 (área em amarelo). A montante da área de estudo o leito do canal é predominantemente rochoso, com seções transversais que possuem dimensões muito reduzidas com relação à escala adotada neste estudo. Conforme observado em campo, o processo dominante nessa área é a erosão do leito e das margens, resultando no alargamento e principalmente aprofundamento do canal. Isso ocorre devido às mudanças impostas ao regime hidrológico da bacia, induzidas pela impermeabilização do solo da área urbana (ver delimitação da área urbana na Figura 8), que resultam no aumento do escoamento superficial e consequente aumento da magnitude das ondas de cheia. Os depósitos fluviais também são muito restritos nesse setor de montante, o que não permite sua avaliação conforme proposto nesta metodologia.

O setor final do ribeirão não foi incluído neste estudo por outro motivo. Nessa área não foram observadas alterações morfológicas e/ou planimétricas ao longo da série de dados orbitais, tanto no canal principal quanto na cobertura superficial dos depósitos, a qual permaneceu com 0 mesmo padrão de vegetação ao longo das datas observadas. A interpretação sugerida para 0 fato de que as mudanças no sistema fluvial têm ocorrido no setor de montante, entre as cabeceiras de drenagem e até aproximadamente $13 \mathrm{~km}$ (ao longo do eixo do vale aluvial), é de que as mudanças hidrológicas que ocorreram nesse setor da bacia hidrográfica, mais especificamente na área urbana, alteraram fortemente a dinâmica do sistema fluvial, assim como ocorreu em outras drenagens do noroeste do Paraná (MONTANHER, 2013). No entanto, deve 
haver algum alcance desses efeitos à jusante, em que, para este estudo de caso, estima-se de aproximadamente $13 \mathrm{~km}$.

Figura 8 - Localização da área de estudo. A - Município de Umuarama em destaque no Estado do Paraná (em vermelho). B - Detalhe para a área de estudo. Bacia do ribeirão Pinhalzinho II em linha branca, o canal principal está representado em azul e a área selecionada para estudo em linha amarela. A área urbana está em vermelho (com grau de transparência).

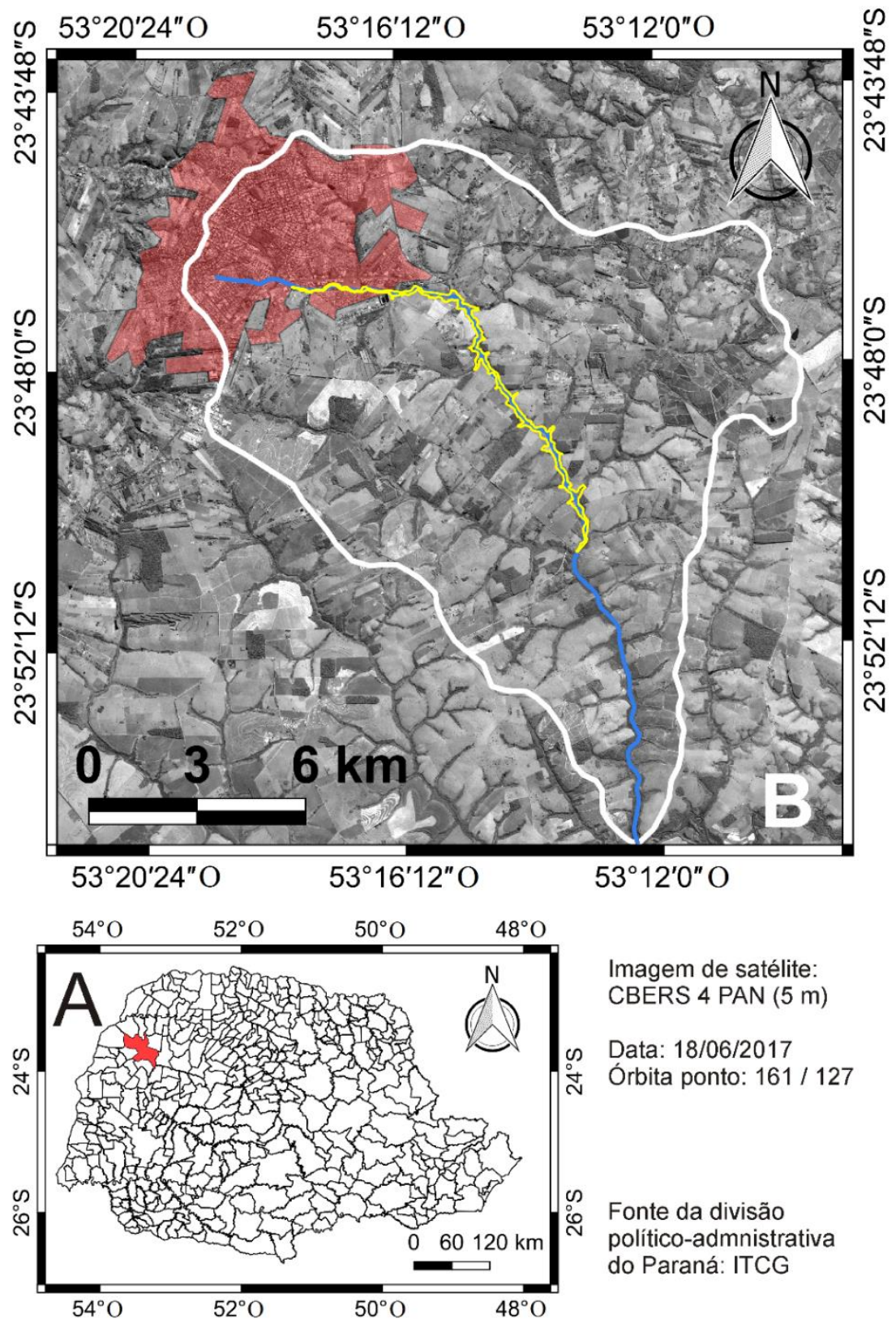

Para o levantamento das variáveis foram utilizadas 15 imagens para o período entre 2004 e 2017, descritas na Tabela 2. Foram utilizadas composições coloridas de alta resolução $(0,5 \mathrm{e}$ 0,65 m) disponíveis no software Google Earth (2017) e imagens do programa CBERS (INPE, 2017). Todas as imagens passaram por processo de georreferenciamento a partir de coordenadas adquiridas em campo, incluindo as composições coloridas naturais provenientes do Google Earth. Nesse caso, as imagens foram obtidas pelo software, georreferenciadas e integradas ao banco de dados no QGIS. Com relação às limitações impostas pelas diferentes 
resoluções espaciais, todas as imagens foram utilizadas para o levantamento do canal principal (em um único vetor linear para cada data) e para a classificação dos sedimentos expostos. Já as imagens do sensor PAN (CBERS 4) não foram utilizadas para o mapeamento da largura do canal, devido à sua menor resolução espacial $(5 \mathrm{~m})$, não compatível com a maior parte das medições feitas.

Tabela 2 - Descrição dos dados de sensoriamento remoto utilizados no estudo de caso

\begin{tabular}{|c|c|c|c|c|c|}
\hline Satélite & Sensor & Órbita / ponto & Resolução (m) & Data & Fonte \\
\hline & Quickbird & & 0,65 & $02 / 07 / 2004$ & Google Earth \\
\hline & Quickbird & & 0,65 & $14 / 12 / 2005$ & Google Earth \\
\hline CBERS 2B & $\mathrm{HRC}$ & $161 \mathrm{D} / 1271$ & 2,7 & $10 / 08 / 2008$ & INPE - DGI \\
\hline CBERS 2B & $\mathrm{HRC}$ & $161 \mathrm{D} / 1271$ & 2,7 & $18 / 12 / 2008$ & INPE - DGI \\
\hline & HRC & $161 \mathrm{D} / 1271$ & 2,7 & $08 / 03 / 2010$ & INPE - DGI \\
\hline & Quickbird & & 0,65 & $21 / 08 / 2012$ & Google Earth \\
\hline & CNES / Airbus & & 0,5 & $01 / 05 / 2013$ & Google Earth \\
\hline CBERS 4 & PAN & $161 / 127$ & 5 & $12 / 08 / 2015$ & INPE - DGI \\
\hline CBERS 4 & PAN & $161 / 127$ & 5 & $28 / 04 / 2016$ & INPE - DGI \\
\hline \multicolumn{3}{|c|}{ CNES / Airbus } & 0,5 & $26 / 06 / 2016$ & Google Earth \\
\hline CBERS 4 & PAN & $161 / 127$ & 5 & $01 / 10 / 2016$ & INPE - DGI \\
\hline CBERS 4 & PAN & $161 / 127$ & 5 & $13 / 01 / 2017$ & INPE - DGI \\
\hline CBERS 4 & PAN & $161 / 127$ & 5 & $27 / 04 / 2017$ & INPE - DGI \\
\hline CBERS 4 & PAN & $161 / 127$ & 5 & $18 / 06 / 2017$ & INPE - DGI \\
\hline CBERS 4 & PAN & $161 / 127$ & 5 & 09/08/2017 & INPE - DGI \\
\hline
\end{tabular}

\section{ESTUDO DE CASO: RESULTADOS E DISCUSSÃO \\ PINHALZINHO II: SÍNTESE ESPAÇO-TEMPORAL}

Para obtenção do produto de síntese para os sedimentos expostos, foram classificadas por meio da técnica de máxima verossimilhança as 15 imagens do estudo de caso (Tabela 2). Para cada imagem foram colhidas entre 10 e 15 amostras de cada classe ("sedimentos expostos" e "outros"). Foram obtidos, para essas classificações, índices Kappa acima de 0,95. Atribuiu-se o valor 1 para as áreas de sedimento exposto, e o valor 0 para o restante da cena (Figura 9). A Figura 9 apresenta os resultados da classificação dos sedimentos expostos, bem como as respectivas imagens, para o mesmo local, ao longo de quatro datas. Pode-se observar a expressiva dinâmica da área, cujas áreas de sedimentos expostos modificam-se muito no decorrer do tempo.

Analisando-se a série de classificações para a área representada na Figura 9 notou-se que para os anos de 2004 e 2005 havia extensas áreas de sedimentos expostos, tanto em barras (de pontal, laterais, centrais), quanto em depósitos sobre a planície (depósitos de rompimento de diques marginais). Para o período compreendido entre os anos de 2008 e 2013 houve uma contínua retração da área de sedimentos expostos devido ao desenvolvimento da vegetação sobre esses depósitos, de forma que a maior parte das manchas de sedimentos observadas foram de barras de pontal (Figura 9 - ano de 2012). As imagens obtidas a partir de 2015 registram um novo episódio de acúmulo de sedimentos sobre a planície, de forma que a área classificada de sedimentos expostos aumenta consideravelmente (Figura 9 - ano de 2016).

Intensos processos de erosão e transporte de sedimentos ocorreram (estando ainda ativos) no setor de montante do ribeirão Pinhalzinho II, os quais podem ser interpretados a partir do produto síntese (Figura 10), obtido por meio da aplicação da equação 4. Observa-se que há dois pontos onde houve presença de sedimentos expostos em boa parte das imagens (pontos $A$ e $B$, área 1). A Figura 10 apresenta o produto síntese para três áreas, em que 1 e 2 estão mais próximos à área urbana do que a área 3.

A presença de sedimentos expostos foi mais constante, bem como sua distribuição espacial foi abrangente sobre os setores de montante da planície de inundação. Quando as áreas 1 e 2 são comparadas com a área 3 (Figura 10), observa-se que a formação de barras e a deposição de sedimentos sobre a planície não foram comuns no setor de jusante do ribeirão Pinhalzinho II. A hipótese para explicar essa diferença está associada com a proximidade do setor de montante com a área urbana da bacia. As ondas de cheia provenientes do escoamento superficial urbano 
possivelmente possuem maior capacidade e competência de transporte de sedimentos, bem como seu retrabalhamento e distribuição sobre a planície. À medida que a onda de cheia propaga-se para jusante, e sua energia diminui, consequentemente ocorre menos retrabalhamento de sedimentos.

A técnica utilizada para a classificação das imagens foi a de máxima verossimilhança. $O$ fato de que boa parte dos sedimentos expostos na área de estudo são constituídos por quartzo (principalmente branco ou transparente) fez com que houvesse uma diferenciação espectral com relação à vegetação que permitisse sua classificação por meio de bandas pancromáticas. Para outras áreas de estudo, no entanto, recomenda-se avaliar a condição local. Sedimentos argilosos, por exemplo, podem não ser tão bem distinguidos da vegetação. A disponibilidade de imagens multiespectrais (ou até hiperespectrais), bem como o uso de técnicas de classificação mais robustas, certamente resultam em classificações mais precisas. Ao se aplicar esta metodologia em aluviões maiores, pode-se utilizar sensores de menor resolução espacial (entre $10 \mathrm{~m}$ e $30 \mathrm{~m}$, por exemplo), cujos produtos estão disponíveis gratuitamente (imagens CBERS, LANDSAT e SENTINEL), os quais permitiriam a aplicação de técnicas multiespectrais.

Figura 9 - Imagens orbitais e resultados da classificação das áreas de sedimentos expostos para quatro
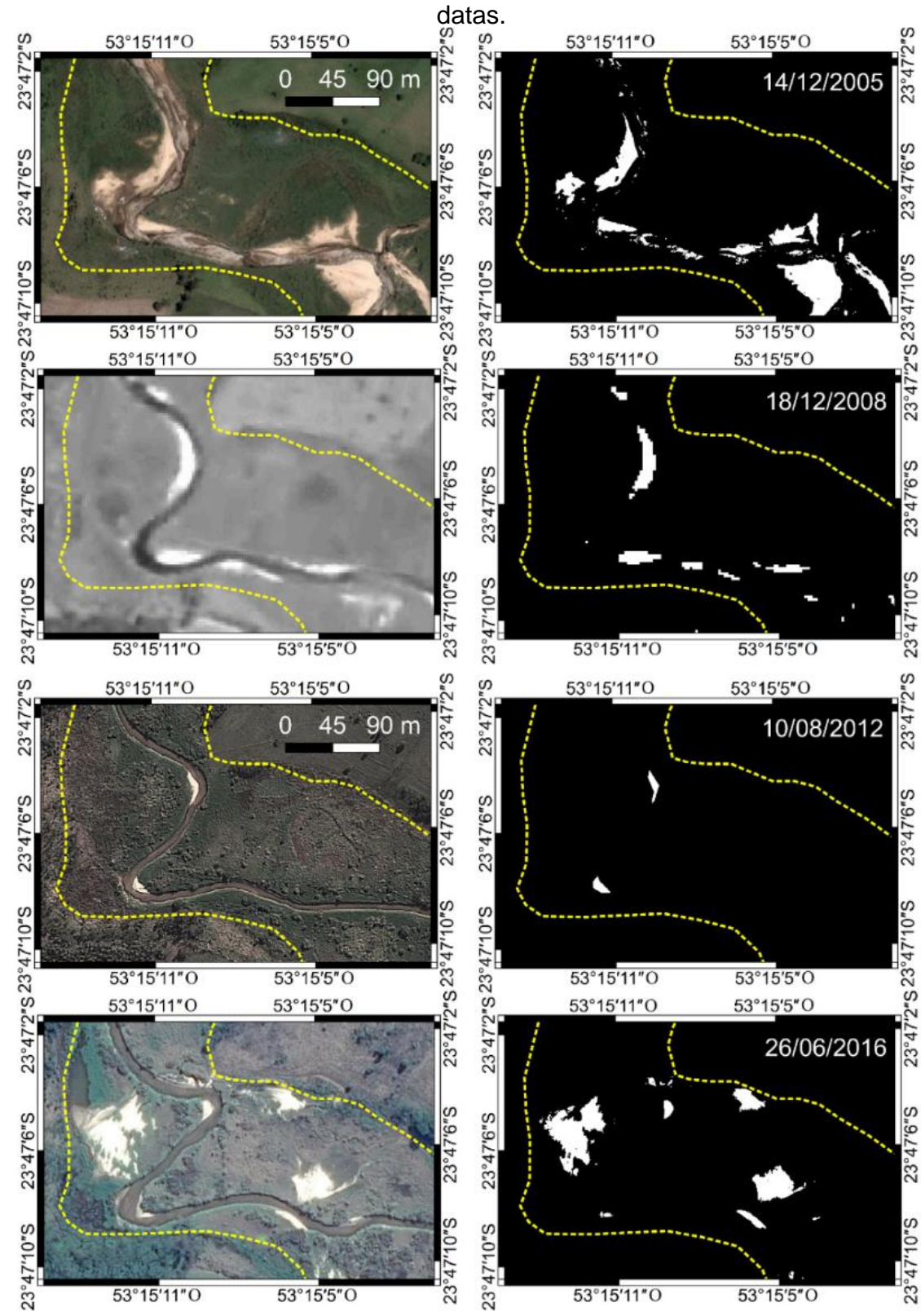
A área do canal do ribeirão Pinhalzinho Il foi mapeada a partir das imagens de maior resolução espacial, provenientes do Google Earth e do sensor HRC (CBERS 2B), em sete anos (2004, $2005,2008,2010,2012,2013$ e 2016). Conforme descrito na metodologia, atribuiu-se o valor 1 para cada polígono, o qual posteriormente foi transformado em arquivo matricial. A partir desses sete arquivos matriciais, aplicou-se a equação 5 , cujos resultados podem ser observados nas Figuras 11 e 12 (a legenda das classes encontra-se na Figura 12). Foi utilizado um gradiente de cores para essa representação, em que a cor vermelha foi adotada para os locais onde o canal esteve em maior número de datas $(100 \%$, por exemplo) e o laranja claro para os locais onde 0 canal esteve em apenas uma data (14,28\%).

Intensos processos de erosão marginal ocorreram no setor de montante do ribeirão Pinhalzinho II, os quais podem ser interpretados a partir do produto síntese representado na Figura 11. Observa-se que nessa área há dois pontos onde houve intensa mobilidade do canal (pontos $\mathrm{A} e$ $\mathrm{B}$, os mesmos demarcados na Figura 10), cujas imagens orbitais que serviram de base para 0 mapeamento podem ser consultadas, para os anos de 2004 e 2016 . Entre os dois pontos de erosão marginal pronunciada observa-se um trecho de baixa mobilidade, enquanto à jusante do ponto $B$ se encontra um setor onde o canal esteve estável durante o período analisado.

O trecho representado na Figura 11 faz parte do setor de montante, próximo à área urbana, cujo canal recebe grandes volumes de água durante as chuvas intensas. Neste setor, a maior energia disponível pode estar atuando no sentido de erodir as margens em trechos meandrantes, diminuindo a sinuosidade local. Outra explicação possível seria no caso de haver desníveis altimétricos locais, que poderiam alterar a dinâmica de fluxo, aumentando a interação águasedimento. Muito embora o produto síntese não possa responder essas questões de ordem física, ele pode orientar as questões a serem analisadas, o estabelecimento de hipóteses e a definição de locais para levantamento detalhado em campo.

Em escala menor do que a utilizada para a Figura 11, a Figura 12 apresenta uma visão sinótica de boa parte da área de estudo. Nesse caso, pode ser observada a dominância de certos tipos de processos em cada setor do sistema. No setor de montante, mais próximo da área urbana (A), é comum o processo de migração de meandros (indicado com o número 2) em uma taxa que alcançou dezenas de metros por ano, nos casos mais extremos. No setor de jusante, por sua vez, é mais comum o processo de avulsão (3), cujos novos canais atingiram alguns quilômetros de extensão. Trechos com canais estaveis para o período também podem ser observados em alguns pontos dos dois setores (1).

Figura 10 - Representação da síntese espaço-temporal de sedimentos expostos para a planície de inundação do ribeirão Pinhalzinho II no setor de montante (1 e 2) e jusante (3). Observe que as escalas espaciais são distintas.

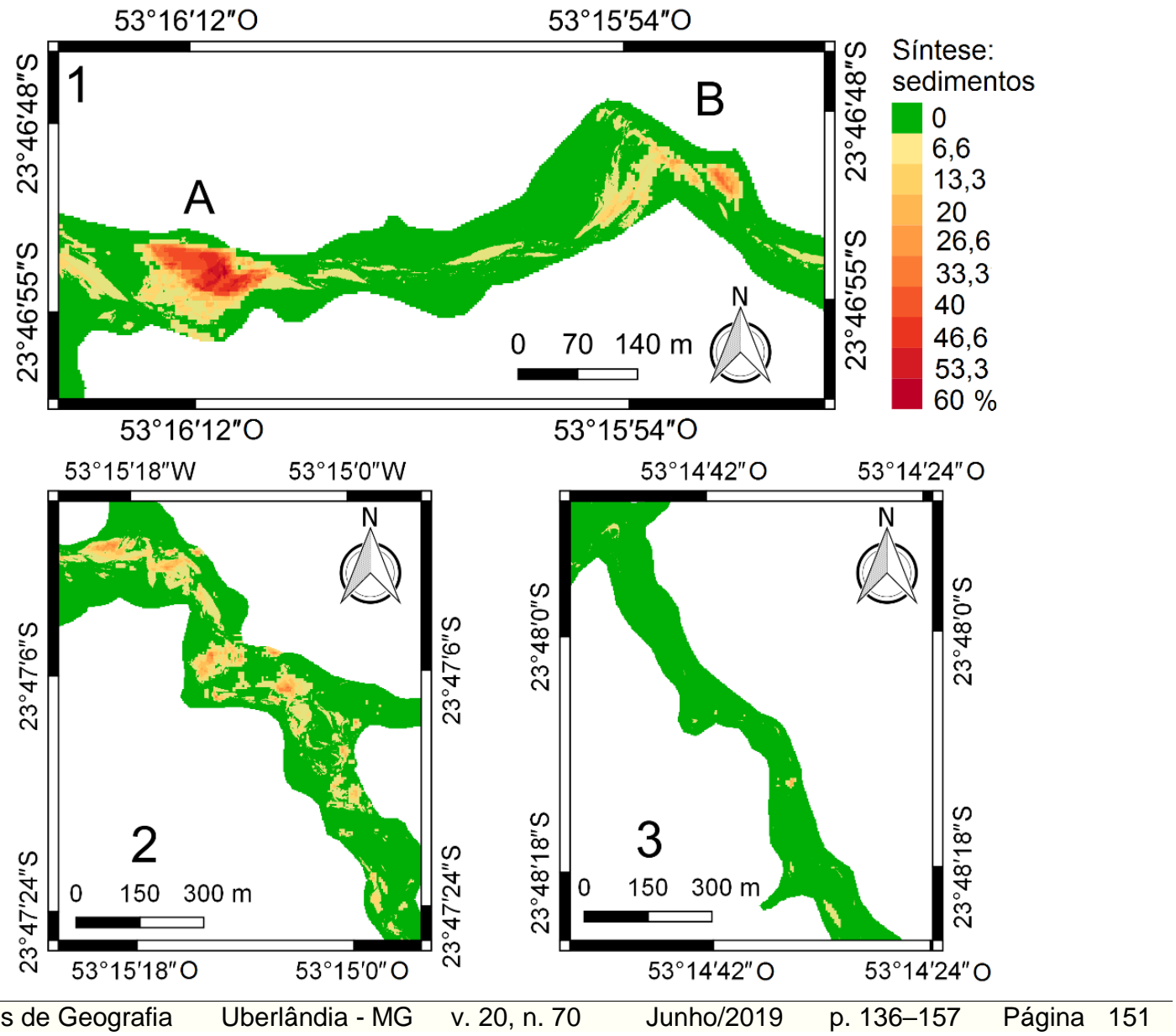


A interpretação sugerida para a diferença entre os tipos de mudança do canal nos dois setores é de que a influência que as ondas de cheia possuem sobre o canal é diferente entre eles. A onda de cheia deve dispender mais energia ao entrar no sistema fluvial, no setor de montante, carreando sedimento grosseiro (areia) e erodindo margens com maior intensidade do que no setor de jusante, onde a erosão marginal seria menor e as partículas transportadas seriam mais finas (silte e argila). Adicionando essa interpretação com as informações obtidas por meio da síntese 1 (dinâmica dos sedimentos), pressupõem-se que o setor de montante apresenta um padrão típico de rios aluviais meandrantes. O setor de jusante, por outro lado, possui um canal com menor mobilidade lateral e avulsões de magnitude quilométrica, características mais semelhantes ao de um padrão anastomosado (embora não seja um padrão anastomosado típico).

\section{PINHALZINHO II: SÍNTESE LONGITUDINAL}

Após a delimitação do eixo do vale do Ribeirão Pinhalzinho II, este foi dividido em segmentos com equidistância de $150 \mathrm{~m}$. Como o trecho total possui $12.600 \mathrm{~m}$, foram definidos 84 segmentos de análise. Foram feitos testes com outras equidistâncias, cujos resultados não estão apresentados neste artigo. Observou-se que, para esse sistema fluvial, equidistâncias menores $(50 \mathrm{~m})$ fizeram com que pequenas mudanças nas variáveis fossem registradas, dificultando a análise de padrões ao longo do perfil longitudinal. Equidistâncias maiores (300 m), por outro lado, fizeram com que se perdessem detalhes, por exemplo na avaliação da evolução meandros e de margens erosivas. Portanto, esse passo é extremamente importante, devendo ser definido pelo usuário. De forma geral, quanto maior a área do sistema que se está avaliando, pode-se ampliar a equidistância de amostragem.

Figura 11 - Representação em detalhe do produto de síntese espaço-temporal do canal do ribeirão Pinhalzinho II. Os quadros que contêm as imagens orbitais referem-se aos locais indicados no mapa síntese ( $\mathrm{A}$ e $\mathrm{B})$ em duas datas.

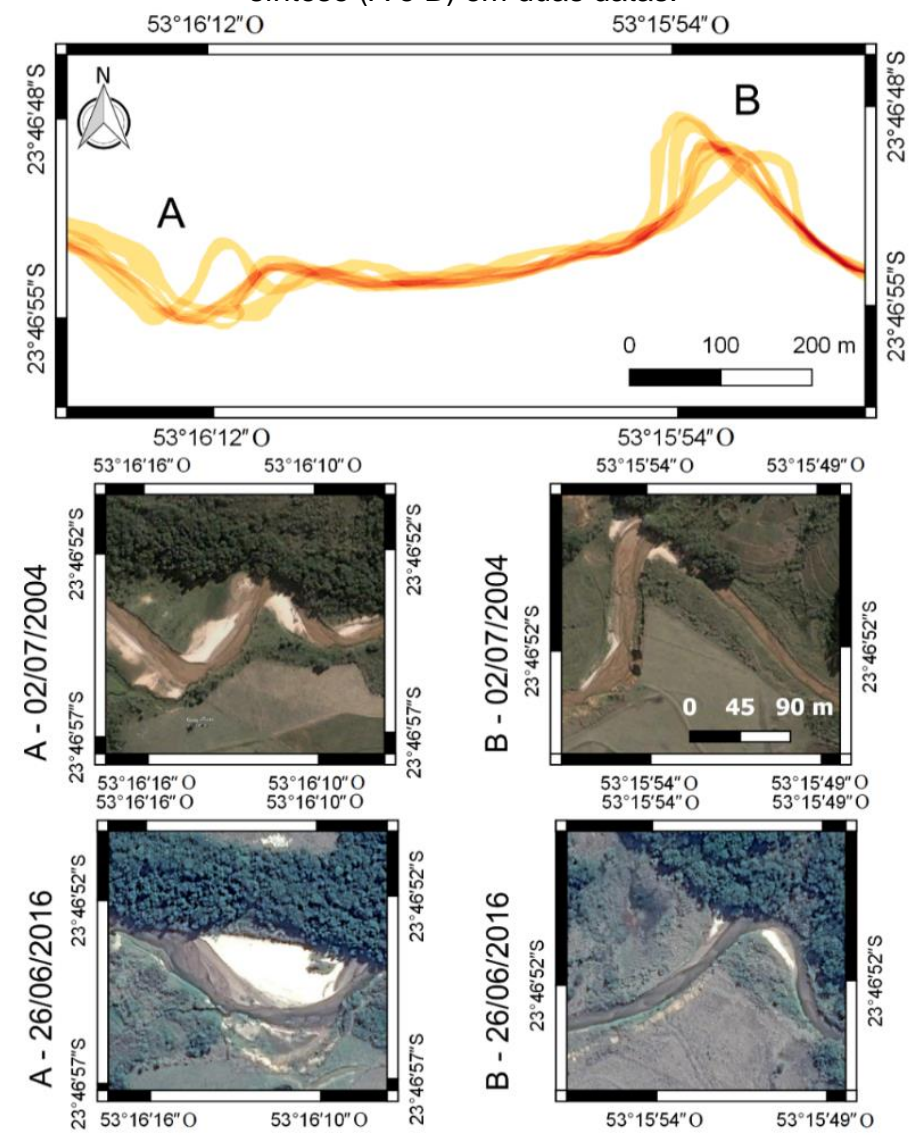


Observa-se que a largura média do canal variou significativamente, tanto ao longo do tempo quanto ao longo do perfil longitudinal (Figura 13A). Para os anos de 2004 e 2005, o canal apresentou as maiores seções no trecho compreendido entre $2.500 \mathrm{~m}$ e $6.000 \mathrm{~m}$ do perfil longitudinal, que corresponde ao setor de transição entre a área urbana (montante) e a área rural (jusante). Nos anos de 2008 e 2010, o canal apresenta um padrão de estreitamento para o trecho supracitado. Durante os anos de 2012 e 2013 houve, localmente, alguns setores de alargamento das seções (por volta de 2.000, 4.000 e $10.000 \mathrm{~m}$ do perfil longitudinal). Finalmente, o ano de 2016 registra um novo ciclo de alargamento das seções, tanto para o setor de montante quanto para o setor de jusante.

O fato de que a largura das seções variou significativamente para o período analisado, principalmente ao redor de $4.000 \mathrm{~m}$ do perfil longitudinal, é concordante com os resultados obtidos a partir da classificação das áreas de sedimentos expostos e de sua síntese (Figuras 9 e 10). De fato, nas áreas com maior variação da largura das seções transversais é também onde houve as maiores variações das áreas cobertas por sedimentos (Figura 13C). Os dados demonstrados pela síntese longitudinal (Figura 13) corroboram a hipótese de um canal com maior mobilidade e dinâmica de transporte de sedimentos, no setor de montante, enquanto 0 setor de jusante é mais estável. Um limite aproximado para essas duas áreas é por volta de $6.500 \mathrm{~m}$ do perfil longitudinal.

A interpretação é a de que as ondas de cheia, geradas pelo escoamento urbano, possuem capacidade de carrear a carga de sedimentos mais grosseiros (areia) para esse setor de grandes mudanças morfológicas. À jusante de aproximadamente $6.500 \mathrm{~m}$, as frações mais finas são transportadas, levando a modificações distintas, como as avulsões. A Figura 13 ainda apresenta os valores de taxa de variação temporal da largura das seções (13B, $\Delta \mathrm{L}$ ) e área de sedimentos expostos (13D, $\triangle A_{E}$ ), os quais são exemplos de aplicação da equação 6.

Figura 12 - Representação da síntese espaço-temporal do canal do ribeirão Pinhalzinho II no setor de montante (A) e jusante (B). Observe que as escalas espaciais são distintas.
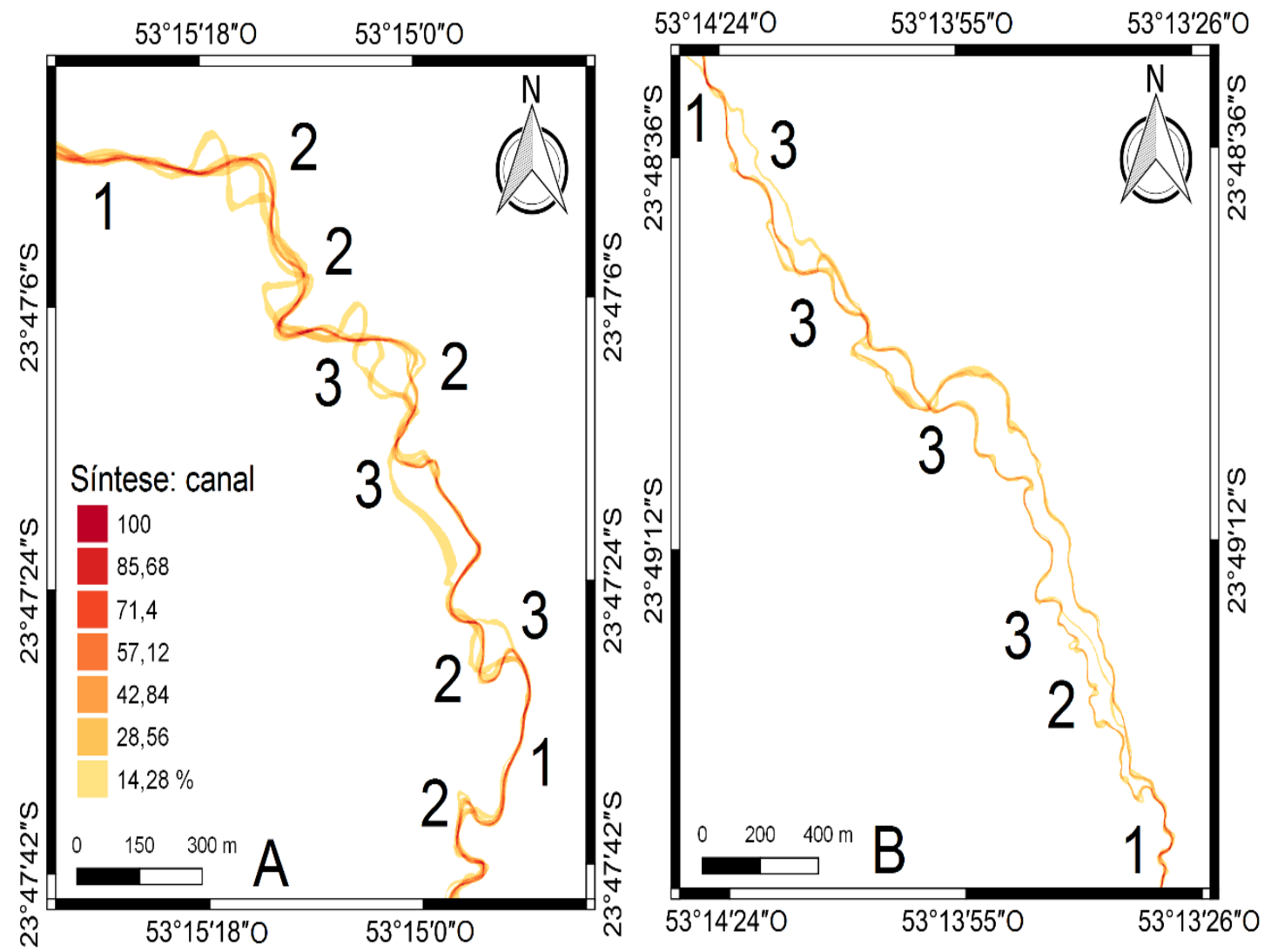
Figura 13 - Produto de síntese longitudinal. Largura das seções $(A)$ e sua taxa de variação temporal (B). Área de sedimentos expostos (C) e sua taxa de variação temporal (D).
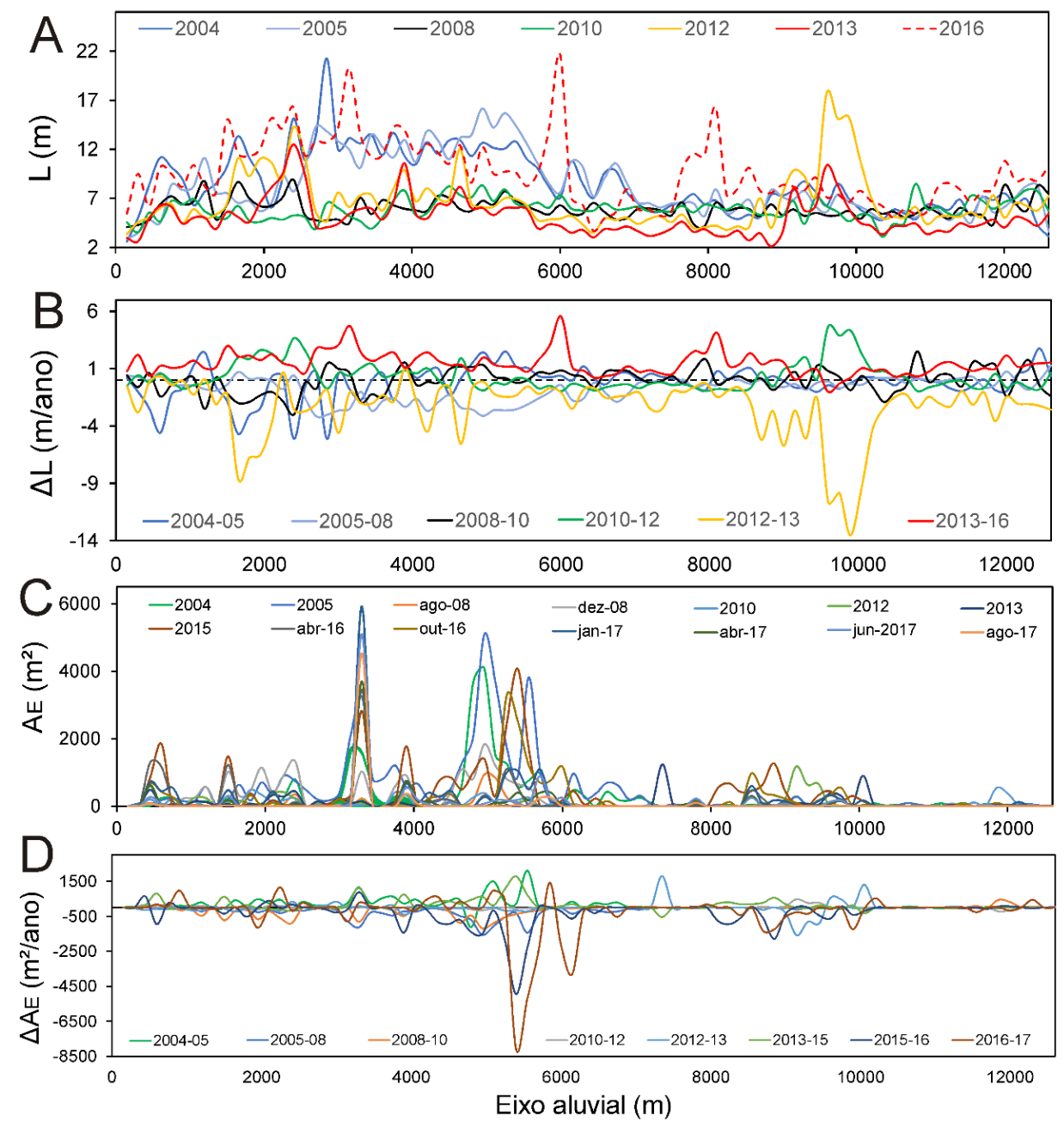

\section{CONSIDERAÇÕES FINAIS}

Este trabalho pretendeu apresentar uma metodologia, consistida de uma sequência de procedimentos para o levantamento e análise de dados sobre mudanças morfológicas em sistemas fluviais. Os dados primários baseiam-se em produtos de sensoriamento remoto, os quais permitem a avaliação espacialmente contínua das mudanças, bem como permite a recuperação do histórico do sistema. Para aplicação desta metodologia, é necessário utilizar técnicas de geoprocessamento, das quais algumas estão descritas em detalhe neste artigo, a partir do uso do software livre QGIS. Outros procedimentos para obtenção de novos produtos, não descritos neste artigo, podem ser posteriormente desenvolvidos. Portanto, pretende-se dar continuidade a esta metodologia, com a descrição de procedimentos para: i) quantificação da taxa de migração do canal; ii) análise da variância das variáveis; iii) geração de produtos espaciais das mudanças entre duas datas e iv) geração de um índice para quantificação da morfodinâmica fluvial.

Com relação aos produtos para análise das mudanças espaço-temporais, a síntese 1 pode ser usada para interpretação de processos como a evolução e retrabalhamento de barras fluviais, a deposição de sedimentos sobre as planícies, como em depósitos de rompimento de diques marginais, por exemplo, e o desenvolvimento da vegetação sobre os sedimentos. A síntese 2, por outro lado, refere-se à análise da mobilidade do canal, sendo útil para avaliação de processos como: alargamento/estreitamento de seções, erosão marginal, migração de meandros e avulsão de canais. 
O produto de síntese longitudinal não permite avaliar a distribuição bidimensional em detalhe dos processos mencionados nos produtos síntese 1 e 2 . No entanto, a síntese longitudinal permite a avaliação espacialmente contínua, em larga escala, do sistema. A síntese longitudinal, neste estudo de caso, deixou clara a diferença entre os principais setores do ribeirão Pinhalzinho II, de montante e jusante. O setor de montante está mais susceptível às fortes ondas de cheia provenientes da área urbana do município de Umuarama, enquanto que o setor de jusante está mais afastado. A interpretação dos produtos fornecidos pela metodologia apresentada leva ao entendimento de que tais setores possuem padrões distintos, basicamente pela diferença de energia das ondas de cheia e no tipo e quantidade de carga sedimentar transportada em cada setor. Para confirmar as hipóteses levantadas neste estudo de caso, no entanto, seria necessário levantar dados adicionais em campo, tanto da textura dos sedimentos nas áreas mencionadas, quanto do perfil longitudinal em detalhe.

É necessário deixar claro que o uso do ribeirão Pinhalzinho II como área de estudo não teve como objetivo sua análise geomorfológica propriamente dita, de forma aprofundada, e sim para fins de exemplificação dos produtos obtidos pela aplicação da metodologia aqui descrita. As discussões geomorfológicas feitas, assim, foram apenas para demonstrar quais questões e interpretações poderiam ser obtidas em um caso específico, a partir da aplicação da metodologia proposta.

\section{AGRADECIMENTOS}

Este artigo é produto do projeto "Análises geoambientais de atividades modificadoras da dinâmica do meio físico em bacias hidrográficas do norte/noroeste do estado do Paraná e bacias correlatas", voltado à dedicação exclusiva na Universidade Estadual de Maringá. Agradeço, portanto, ao apoio institucional da UEM e às críticas e sugestões dos revisores, principalmente pelos apontamentos de erros conceituais ao longo do texto.

\section{REFERÊNCIAS}

BERTALANFFY, L. V. Teoria geral dos sistemas. 8 ed. Petrópolis: Editora vozes. 2015.

BERTRAND, G. Paisagem e geografia física global. Esboço metodológico. RA'E GA, n. 8, p. 141-152, 2004. https://doi.org/10.5380/raega.v8i0.3389

CHRISTOFOLETTI, A. Geomorfologia. 2 ed. São Paulo: Edgard Blücher, 1980.

OWNWARD, S. R.; GURNELL, A. M.; BROOKES, A. A methodology for quantifying river channel planform change using GIS. In: Variability in Stream Erosion and Sediment Transport. Anais... Canberra. IAHS Publ. no. 224, 1994.

FRAGAL, E. H.; ALVES, F. C.; SOUZA FILHO, E. E. A influência da inundação na dinâmica da vegetação da planície fluvial do alto rio Paraná em 2007. Revista Brasileira de Geomorfologia, v. 13, n. 3, p. 299-310, 2012. https://doi.org/10.20502/rbg.v13i3.229

FRANÇA JUNIOR, P. Análise do uso e ocupação da bacia do córrego pinhalzinho II utilizando geoindicadores, Umuarama-PR, 1970-2009. Dissertação (Mestrado em Geografia) - Maringá: UEM. 2010.

FRANÇA JUNIOR, P.; SOUZA, M. L. Tecnógeno em ambientes fluviais: noroeste do Paraná, Brasil. Quaternary and Environmental Geosciences. V. 5, n. 2, p. 45-52. 2014.

https://doi.org/10.5380/abequa.v5i2.34777

GILVEAR, D.; BRYANT, R. Analysis of Aerial Photography and Other Remotely Sensed Data. In: KONDOLF, G. M.; PIÉGAY, H. (Eds.) Tools in fluvial geomorphology. New York: Wiley, 2003. p. 135-70. https://doi.org/10.1002/0470868333.ch6

GOOGLE EARTH. 7.3. 2017. Disponível em: <https://www.google.com.br/intl/pt-

BR/earth/download/gep/agree.html>. Acesso em: 17 de outubro de 2017.

$\begin{array}{lllll}\text { Caminhos de Geografia } & \text { Uberlândia - MG } & \text { v. 20, n. } 70 & \text { Junho/2019 } & \text { p. 136-157 Página } 155\end{array}$


Levantamento de dados e análise de mudanças em sistemas

fluviais por meio de geoprocessamento e sensoriamento

remoto: proposta metodológica e estudo de caso

Otávio Cristiano Montanher

GOLLY, A.; TUROWSKI, J. M. Deriving principal channel metrics from bank and long-profile geometry with the R package cmgo. Earth Surface Dynamics. v. 5, p. 557-570, 2017.

https://doi.org/10.5194/esurf-5-557-2017

GREGORY. K. J. (Ed.) River channel changes. Nova York: John Wiley \& Sons. 1977. 448 p.

GREGORY, K. J. The human role in changing river channels. Geomorphology, v.79, n. 3-4, p. 172-191, 2006. https://doi.org/10.1016/j.geomorph.2006.06.018

INPE - Instituto Nacional de Pesquisas Espaciais. INPE/DGI - Divisão de Geração de Imagens. 2017. Disponível em: <http://www.dgi.inpe.br/siteDgi/portugues/index.php>. Acesso em: $30 \mathrm{de}$ maio de 2017.

KLEINA, M.; PAULA, E. V.; SANTOS, L. J. C. Análise comparativa dos estilos fluviais do rio sagrado (Morretes/PR) para os anos de 2006 e 2011. Revista Geografar, v.9, n.1, p.27-44, 2014. https://doi.org/10.5380/geografar.v9i1.35229

LEYS, K. F.; WERRITTY, A. River channel planform change: software for historical analysis. Geomorphology. v. 29, p. 107-120, 1999. https://doi.org/10.1016/S0169-555X(99)00009-4

MARTINELLI, M. Mapas da geografia e cartografia temática. 6 ed. São Paulo: Contexto. 2016. $142 \mathrm{p}$.

MONTANHER, O. C. Ciclos de erosão e sedimentação em bacias hidrográficas urbanas do noroeste paranaense e suas implicações no ajuste de sistemas fluviais. Revista Brasileira de Geomorfologia. v. 14. n. 4. p. 319-325, 2013. https://doi.org/10.20502/rbg.v14i4.401

MONTANHER, O. C.; SOUZA FILHO, E. E.; MARQUES, M. Variação espacial e temporal da largura do canal do ribeirão pinhalzinho II, Umuarama, PR. Revista Geonorte, v.10, n.1, p. 517522, 2014.

NOVO, E. M. L. M. Sensoriamento remoto: princípios e aplicações. 4 ed. São Paulo: Blucher. 2010. $387 \mathrm{p}$.

OSTERKAMP, W. R.; HUPP, C. R. Fluvial processes and vegetation - Glimpses of the past, the present, and perhaps the future. Geomorphology v. 116, n. 3-4, p. 274-285. 2009.

https://doi.org/10.1016/i.geomorph.2009.11.018

PINTON, L. G.; CUNHA, C. M. L. O uso de geoindicadores em paisagem rural: subsídios à análise das mudanças morfológicas antropogênicas da bacia do córrego do cavalheiro Analândia (SP). Revista do Departamento de Geografia, v. 29, p. 1-19, 2015.

https://doi.org/10.11606/rdg.v29i0.102128

QGIS DEVELOPMENT TEAM. QGIS Geographic Information System. Open Source Geospatial Foundation. 2009. Disponível em: <http://qgis.osgeo.org>. Acesso em: 30 abr. 2017.

QUEIROZ, P. H. B.; PINHEIRO, L. S.; CAVALCANTE, A. A.; TRINDADE, J. M. R.

Caracterização multitemporal de barras e ilhas fluviais no baixo curso do rio Jaguaribe, CearáBrasil. Revista Brasileira de Geomorfologia. v. 19, n. 1, p. 167-186, 2018.

https://doi.org/10.20502/rbg.v19i1.1282

R CORE TEAM. R: A language and environment for statistical computing. R Foundation for Statistical Computing, Vienna, Austria. 2017. Disponível em: <https://www.R-project.org/>. Acesso em: 02 mar. 2017.

RODRIGUES, C. Morfologia original e morfologia antropogênica na definição de unidades espaciais de planejamento urbano: exemplo na metrópole paulista. Revista do Departamento de Geografia, v. 17 101-111, 2005. https://doi.org/10.7154/RDG.2005.0017.0008 
SANTOS, G. F.; PINHEIRO, A. Transformações Geomorfológicas e Fluviais Decorrentes da Canalização do Rio Itajaí-Açu na Divisa dos Municípios de Blumenau e Gaspar (SC). Revista Brasileira de Geomorfologia, v. 3, n. 1, p. 1-9, 2002. https://doi.org/10.20502/rbg.v3i1.10

SCHUMM. S. A. The fluvial system. Nova York: John Wiley \& Sons. 1977. 338 p.

SCHWENK, J.; KHANDELWAL, A.; FRATKIN, M.; KUMAR, V.; FOUFOULA-GEORGIOU, E. High spatiotemporal resolution of river planform dynamics from Landsat: The RivMAP toolbox and results from the Ucayali River. Earth and Space Science. v. 4, p. 46-75, 2017.

https://doi.org/10.1002/2016EA000196

SOUZA FILHO, E. E.; FRAGAL, E. H. A influência do nível fluviométrico sobre as variações de área de água e da cobertura vegetal na planície do alto rio Paraná. Revista Brasileira de Geomorfologia, v.14, n.1, p. 81-92, 2013. https://doi.org/10.20502/rbg.v14i1.378

STEVAUX, J. C.; LATRUBESSE, E. M. Geomorfologia Fluvial. São Paulo: Oficina de Textos. 2017. $336 \mathrm{p}$.

STRAHLER, A. N. Equilibrium theory of erosional slopes approached by frequency distribution analysis. American Journal of Science. n. 248, p. 673-696, 1950.

https://doi.org/10.2475/ajs.248.10.673

TRICART, J. Ecodinâmica. Rio de Janeiro: IBGE, SUPREN. 1977. 97 p.

Recebido em: 16/05/2018

Aceito para publicação em: 23/01/2019 